\title{
Simulation Exercises for the Teaching of Planning: The Example of Ruritania
}

\section{Gavin Kitching}

\section{Genesis of the exercise}

Since I came to the Centre with strong interests in political and economic theory, I was asked by colleagues to take over the teaching of the 'Planning Theory' element in the $\mathrm{MSc}$ in Social Planning upon the retirement of Mrs. Nancy Baster, and I spent a year (1974-75) in reading and attending the course in preparation for this. I found the reading in particular a very frustrating experience since most of the texts on 'Planning Theory' appeared to work at a level of generality which $I$ at least found very unilluminating. In fact the literature on development planning seemed to divide rather broadly into three types. The first was concerned with economic development planning as traditionally conceived which, after devoting a few, usually rather trite, chapters to 'theory', concentrated heavily on planning techniques. (Tinbergen 1967: Griffin and Enos 1971) The second type consisted of studies of actual development planning practice, usually by country, sometimes by intra or inter-country region, with Waterston's massive survey at its head. (Waterston 1966; Hanson 1966; Friedmann 1966) The Third (with which I was primarily concerned) concentrated on 'social' development planning. This was perhaps the weakest of the three categories, in the sense that the volume of the literature itself was (and is) very small, and that it was extremely disparate both in content and approach, ranging from country or local studies of education or health policy to repeated discussions of the relationship between social and economic planning, to simplified rehashes (with 'social' material) of marginalist and other planning techniques, to uneasy discussions of the relevance of western social welfare policies and programmes in developing countries. (See starred items under References section.) A great deal of this literature emanates from the UN agencies and was notable for the familiar UN desire not to offend the ideological sensibilities of its various sponsors, with a consequential tendency to skate round political issues.

Thus the initial desire to avoid a traditionally didactic approach to the teaching of planning theory derived from three sources:
1. The highly abstract and general nature of the literature on planning theory, which did not seem likely to give students any 'feeling' for what it was like to plan anything;

2. The limited and rather scrappy nature of the literature on Social Planning in particular, whose 'theoretical' component seemed to replicate the above fault;

3. The enormous gap between theory and practice in development planning revealed by the descriptive literature.

I might also add that I had serious theoretical and philosophical misgivings about most of the literature in planning theory. These concerned both the validity of the Weberian approach to rationality which most of the literature enshrines (means are rational or irrational, ends are not susceptible to judgement in terms of rationality but only in terms of 'values'), and (in another variant) the social control/social consensus assumptions which are necessarily built into 'systems analysis' once it is applied to any social function or institution. Both these matters are fascinating topics of discussion in themselves but cannot be gone into here, since they belong to the more exotic reasons why I eschewed a didactic approach and opted instead for a simulation exercise, the actual experience of which forms the subject of this article.

These then were the reasons why, as an academic, I chose to move in this direction, but as a teacher I was also strongly influenced by another consideration. Nearly all of the students taking the $\mathrm{MSc}$ in Social Planning were middle-level administrators from government and other public agencies in the less developed world. Many of them had not undertaken academic work for a very considerable period, and, more importantly, nearly all of them came from educational backgrounds which emphasize what Freire calls the 'banking' concept of education. That is to say, very many of the students had a strong tendency simply to assimilate and reproduce (often verbatim) didactic material or textbook content. Since a great deal of the literature on planning theory (in particular) is highly jargonised, there tended to be a premium on mastering the jargon and reproducing it correctly, so that critical thought about the 
ideas which it enshrined was delayed or avoided. This passivity, and this strong tendency to concentrate on correct reproduction of what is heard or read, is harmful in any educational context, but it seemed to me absurd in the case of 'planners' or putative planners, who were being trained for an activity which is quintessentially about intervention to change the world, about learning in order to act.

\section{Parameters of the exercise}

The idea of attempting a simulation exercise originally derived from some limited experiments in this area in the original course, and from a reading of $H$. Chenery's World Bank study, Redistribution with Growth (RwG). The latter had two outstanding merits. First, it seemed to provide a good framework within which one could explore the relationship between economic and social planning, and, second, it revealed, by implication, what was wrong with much of the conventional literature in planning theory, i.e. that it is almost totally concerned with the analysis of planning as a set of formal procedures, as a set of means to achieve planning objectives, rather than with the nature of the objectives themselves. Yet it seemed to me a priori quite likely that means and procedures are themselves determined, at least partially, by the nature of the objectives chosen. I came to think, in fact, that much of this literature seemed so arid, general and boring, because it completely abstracted from the question "planning what?". In pursuit of a set of universal generalisations about planning procedure it slipped into vacuity.

Following from this it seemed quite likely that students would learn much more about planning as actual process if they were to set about trying to achieve a policy objective in a planned way. Redistribution with Growth suggested what that objective might be, i.e. to obtain the maxinum possible redistribution of real incomes for the lowest possible diminution of the rate of growth of GNP. I therefore set about creating a country which had a 'moderate' degree of income inequality (using the World Bank study's criteria), but with significant variations in the degree of inequality by region (I gave Ruritania four ecological/economic regions). Students were informed that the rate of growth of GNP had been 7 per cent in the first five-year plan (1970-75), and that the task of the seminar group (now constituted as a Planning Commission) was to reduce income inequality by the nraximum amount compatible with the minimum possible reduction in this growth rate. No further policy guidelines were provided, i.e. there were no target figures specified either for income distribution or for the minimum acceptable rate of growth, nor were any time horizons laid down for the achievement of the objective. This was quite deliberate, since I wished to see what students could achieve in the way of clarification of the objective (and indeed whether they would see that further clarification was necessary), and such vagueness also seemed to me to be typical of policy pronouncements in many Third World countries.

I also deliberately chose to create a 'developing' country of this type rather than to use a real case. I did so primarily because the seminar group contained students from Latin America, Africa, and Asia, and I wanted to create a country with some of whose problems all the students could identify. At the same time, l was anxious to avoid a situation where national or regional loyalties could evoke either defensiveness cr aggressiveness, and to create an atmosphere of disinterestedness and open-mindedness as an essential prerequisite of analytical effort. This does not mean that the exercise avoided ideological or political issues, rather the contrary Precisely because it was not real, middle-level civil servants were able to face up to the political or ideological premises and implications of policies and programmes in a way in which they might not have done had their own or someone else's country been involved.

The creation of a country of this type meant, of course, that data had to be invented rather than discovered. But this constraint, whilst creating problems at times (see below), also guaranteed that the exercise would not grind to a halt if a particular piece of data was not available. Students knew that in one sense no data were 'available', so they were primed from the beginning to use their initiative and ingenuity to obtain them. Nor did this mean that any data could be invented: in practice consistency constraints placed very strict linitations on invention, and were also a crucial part of the learning process.

\section{Issues arising from the exercise}

I wish now to discuss a number of issues which have arisen after two years' experience with the exercise, in 1975-76 and in 1976-77.

\section{Data}

I compiled the original data from national plans, statistical abstracts, economic surveys and income distribution studies, emanating from Kenya, 
Tanzania, Zambia, Pakistan and Peru. Ruritania is in fact a hybrid of these five countries, the hybridisation mainly taking a regional form. Thus Region 1 of Ruritania is a densely populated highland area devoted to tea, coffee and pyrethrum production on peasant smallholdings. Region 2 is smaller, highly urbanised, and produces all the copper which constitutes the country's principal export. Region 3 is a huge central semi-desert populated entirely by pastoral nomads, but also containing the country's second city and only port, and Region 4 consists of wheat-producing latifundia with labour tenants employed by a small traditional aristocracy. In addition to this basic outline description of the country (with physical and political maps) the initial data base comprised:

1. Tabulated results of a household budget survey conducted in 1972: this was the principal source of data on income inequality;

2. A socio-economic outline of eight income categories, concentrating on occupation and place of residence;

3. Tabulated data on regional and urban/rural inequaliites in health and education facilities;

4. Exports, by category and value, 1967 and 1974;

5. Scurces of government revenue, 1973-74;

6. Incidence of direct taxation by income category;

7. Development expenditure in the first Five-Year Plan (1970-75), by principal activities;

8. Urban-rural and regional distribution of this expenditure;

9. Per capita expenditure on health, education and water supply by district;

10. Private sector investment by sector, 1970-75;

11. Urban-rural and regional distribution of this expenditure.

As initially conceived this data base was to provide a very simple outline of the Ruritanian economy and society from which students might begin to formulate a strategy. After this I was to provide further data as required by the process of analysis and policy-making. This proved impossible. The demand for new data generated by the first six seminar sessions was such that satisfying it became an almost full-time activity and began to disturb other work commitments. This was in part because the initial data base had been rather hastily collected and lacked a coherent focus. First attempts to formulate a strategy therefore showed up large gaps (e.g., data on household income but no data on household size or composition). However, this was also perhaps the first lesson taught by the exercise: that planning is a very data-hungry business, and that pursuit of data does not occur in vacuo, but is moulded constantly by the questions raised in the attempt to formulate even a most basic strategy.

Data demands in fact threatened to shipwreck the exercise at a very early stage, until an enthusiastic participant, with extensive planning experience, suggested that data collection should be the responsibility of students working in groups. This was accepted, and added a new dimension to the exercise because it forced students to develop 'data-digging' skills, or to use their ingenuity or personal experience when relevant data were not available from published sources. It also raised sharply questions of data consistency, since students constantly returned to the seminar with data which were incompatible with those in the original data base or with other data collected. This revealed an important point about simulation exercises, which is that although the initial parameters are in one sense arbitrary, specification of only a few of them soon constrains what can be invented. It is no use, for example, inventing output figures for wheat which when compared with the cultivated area yield the magnificent sum of two shillings per hectare (as one student did!).

I suggest that this is an illuminating way of teaching about national accounts and indeed about the inter-dependency of economic and social sectors, and may be of particular value for students without a professional background in economics or social statistics. who may be apprehensive if introduced to these matters in a more formal manner.

\section{Associated reading}

I suggested a small amount of reading of which Redistribution with Growth and the UN study, Social Policy and the Distribution of Income in the Nation, were the most important. However, I was over-optimistic about the comprehensibility of the former to students who had little or no economics background, and so a great deal of the first term's teaching (in both the first and second years of the exercise) was taken up with leading students slowly through this text which I had initially assumed would be mastered before the first session. This problem may be soluble by the preparation of a simplified resume of the book, concentrating on the most relevant sections, and distributed before the session commences. 


\section{Leadership of the seminar}

An essential purpose of the exercise was for students, individually and collectively, to learn to think like planners and analysts by moving off from the initial data base in a direction which they had determined, and then following where the ensuing interaction of new data, objectives and programmes would lead them. Thus in the first year and, to a lesser extent, in this last academic session I have not taken issue with the basic strategy or policies selected, but have restricted myself to pointing out the data implications involved, and inconsistencies between objectives, or between objectives and programmes. I have also suggested alternative objectives or programmes and what would be required for the Commission to make a choice. This 'low profile' approach has had two consequences: it has made the exercise extremely arduous, since one could never be sure what direction it would take in any given week, and what might be required in terms of informational suggestions, analytical or technical skills, or areas of expertise; it has meant that in the absence of leadership, the strategy has been affected by dominant personalities within the group, and, more importantly, by the disciplinary and occupational backgrounds of the MSc group. Thus the first year's group had a strong background in social policy, and there tended to be a heavy emphasis on the 'elimination' of 'poverty' and 'inequality' and an impatience to act rather than waste time on analysis. The net result was that a national plan with a strong social emphasis was half-completed before a random suggestion by a group member produced some balance of payments projections which showed the probability of a large and growing deficit. At this point there was a tendency to jettison the search for income redistribution entirely, and to concentrate on output maximisation and import substitution of the most capital intensive sort. Or again, one had to wait until the second year's group, which included more economists or regional planners, for someone to point out that regional shares of development expenditure could not be regarded as 'fair' or 'unfair' until one knew something about regional contributions to GDP and government revenue.

A non-directive approach to subject matter which is extremely dense and capable of ramifying in a whole variety of directions raises questions about the examinability of this component of a taught MSc, since, by definition, it can have no very predictable 'curriculum', and does not lend itself to ordered progression through 'topics'. Rather, a series of central issues tend to recur, being approached constantly from slightly shifting perspectives and concepts.

It may be, therefore, that in future a more directive approach will be required, though this might prejudice the chances of students developing problem-solving skills and self-confidence. As it is, even with a low profile approach, one has often to discourage uncritical acceptance of, or thankful snatching at, any suggestion made by the 'President' of Ruritania.

\section{Realism}

A central question which arises is how far one can or should attempt to replicate reality. Two questions which arose were firstly whether the Commission should be divided ministerially and/or regionally, and what should be the organisational and political relationship between these sub-groups and the Commission as a whole if this occurred. Since nearly all the students came from government civil service backgrounds, inter-departmental politics was an issue which preoccupied and amused them. Secondly there was the issue of how far 'political' factors such as splits within, or mass opposition to, the government should be incorporated in the exercise. At one stage a colleague even entered the tray as a senior security officer with a confidential report on, among other things, a threatened coup by officers connected to the 'feudal' landlords of Region 4 (whose land the Commission was considering 'reforming').

Experiment in this area soon revealed that if the exercise was to be of any use as a tool for teaching about planning issues these dimensions had to be rigorously excluded, for they tended to monopolise attention, to the almost total exclusion of the analytical and technical issues raised by the data and the slowly evolving plan. In short it was necessary to make rather Fabian assumptions about the neutrality and acceptability of the State as planning and policy making agency to prevent the exercise grinding to a halt.

On the question of how far one can be realistic two further issues arose. Firstly, aside from dividing the planning commission into ministerial working groups (for the purposes of data collection and the preparation of ministerial reports or recommendations to the Commission) I failed to incorporate an organisational or administrative dimension into the exercise. That is to say, there was no systematic modelling of the structure of administration or the organisation of planning in Ruritania, so we have not been able to follow 
through the administrative feasibility or organisational implications of plans and proposals-a major weakness of the current structure of the exercise.

Secondly, the exercise is unable to simulate the crucial dimensions of plan implementation effectively, and whilst questions of feasible 'implementability' of particular objectives or programmes are raised hypothetically, this is a poor substitute for actual formulationimplementation-reformulation which constitutes the process of development planning. In fact a simulation exercise of this type must of necessity be confined to data analysis and plan formulation in an almost total vacuum.

\section{Time}

The Ruritanian Exercise proved to be very expensive in terms of time and effort of both students and staff. During the 1976-77 academic session, when it was functioning for two terms, one seminar session of one and a half hours was devoted to it weekly in the first term, and two sessions, totalling three hours per week, in the second term. In addition I estimate that the most conscientious students spent some eight to ten hours weekly between sessions in data collection and other preparation. I spent 20 hours per week in preparation in the first year, and about 15 hours in the second, although it seems likely that staff preparation time will fall as the exercise becomes established. I attempted to compensate for the heavy burden the exercise placed on students by reducing the load of associated reading to the absolute minimum, but nonetheless, within the structure of a one-year examined MSc there must be some unease about a course component which makes up only one third of one paper in a three paper examination and is of such restricted 'examinability'. It does, however, seem to me that the exercise could be more intensively used, particularly for techniques teaching (see below) and so 'earn its keep' more fully.

\section{Simulation exercises and formal teaching methods}

Whilst I believe that in the teaching of planning, and in dealing with the sorts of students who come to the Centre, simulation exercises and an element of 'discovery learning' have a distinct advantage over more formal methods, it is clear that they cannot entirely replace a didactic element. This is firstly, and most obviously, because the lecture can be a much more intensive and time-saving method of imparting esséntial information, but also because of a pedagogic problem which arises in these sorts of exercises. It is clear that a crucial part of a discovery learning process is the capacity to label correctly what it is one is learning. For example, it is important when a student is deep in a group discussion about the level of compensation to be paid to landlords that he/she should be able to stand back and say "Ah yes, this is an example of the need for consistency between objectives and programmes".

Though this 'labelling' may seem a simple enough process, nearly all the students found it exceedingly difficult, despite the fact that another closely associated lecture course on 'Types and Styles of Planning' had been devised precisely to provide them with a basic planning 'vocabulary'.

\section{Possible developments of the simulation format}

(a) Closer Coordination with techniques teaching: At the present time, a 'Techniques for Social Planners' course accounts for one of three examined papers and includes an assessed exercise. The techniques element is separately taught by means of lectures and seminars and, particularly in the seminars, a large part of the work involves students' use of various techniques (from projections to linear programming) on simulated or real data. Yet by its very nature the Ruritanian Exercise persistently calls for the application of statistical and mathematical techniques as problems are formed and faced (calculation took up around 30 per cent or more of the time in all sessions). Thus it seems to provide the perfect forum for techniques teaching, even if the latter only takes the form of detailed discussion of which technique would be required to solve or illuminate a problem and the likely difficulties of its application. Moreover, the exercise format in itself provides the perfect forum for making an essential point about any and every planning technique, i.e. that such techniques only come into play in a concrete problem-solving context. In addition the exercise continually poses problems relating to the applicability of statistical techniques, and the relationship between value judgements, theoretical or methodological assumptions, and techniques.

(b) Application of the simulation format to other courses: The range of application of the simulation approach to the teaching of planning and management seems considerable, and indeed, if there is a danger it is that of letting it dominate the total structure. In the context of the Swansea MSc in Social Planning, one might for example 
concentrate much more heavily on the regional dimension of Ruritania and base a course in Regional Planning around this format. One could even select a region of the country (or create a new synthetic region with a given set of parameters and problems) for closer concentration on intra-regional issues (rather than the inter-regional focus which tends to be built into a 'country' simulation). There might also be a role (possibly more restricted) for simulation in the analysis of administrative and management problems in planning (e.g. simulating a departmental structure at a national level or a district administrative structure). The central problem, however, of such a preponderant simulation element in a one-year postgraduate course is that of time and preparation.

(c) Computerised simulation exercises: Some students suggested that if the Ruritanian data were computerised, it would be possible for them to 'test out' the effects of alternative policies or programmes in terms of crucial variables (in this case income distribution and the rate of growth), and I am currently examining this possibility. Two points arise however. In the first place computerisation would certainly require the body of basic data to be expanded and made more systematic and internally consistent. More importantly, computerisation would undoubtedly change the nature and direction of the exercise in a way which, while perfectly valid in its own terms, would undermine some of its pedagogic virtues.

One of the central purposes of the exercise is to teach students who are often weak in the areas of economic and social theory about the functioning of an economy, and in particular about the relationships between economic and social sectors and variables. In this process the discipline posed by the needs of data consistency (and brought out in the process of data collection or invention) plays a central role. In fact a great deal of the discussion in seminars is concerned with tracing the possible ramifications of suggested policies or programmes in apparently distant areas. Thus for example one sees how land reform may lower the marketed surplus in the short term. with a consequent need for food imports and a possible increase in the balance of payments deficit. At a further remove, increased food prices are seen to produce the possibility of wage increases, bringing a possible fall in foreign investment, etc., etc. In the tracing of these possible linkages and their policy implications students learn a great deal about how economies and societies operate, and this would be truncated if the exercise were computerised. In computer simulation the linkages are built into the computer programme, and students see the results of them (as crucial variables change in response to a certain input or pattern of inputs) but do not have to think through their actual functional logic. On the other hand, computerised planning simulations have the advantage that students see the results of alternative policies or programmes, and thus can measure them against desired objectives. Without the speed of calculation involved in computerisation this is impossible and has regularly posed problems in the exercise. It may well be, therefore, that two different forms of exercise could be developed, one non-computerised with a basic analytical teaching focus, the other computerised and with a more po:icyother computerised and with a more computational focus.

\section{Conclusions}

I have dealt with by no means all the issues raised by the Ruritanian Exercise, for these have been as many and varied as the subject matter of each exercise session. In particular, for the purposes of this paper I have neglected the issue of student response (which has tended to be polarised between strong enthusiasm and equally strong distaste or unease), nor have I dealt with the problems posed by the informally structured seminar as a teaching form.

However, atter two years' experience I have become convinced that, with all its problems, simulation represents an immensely fruitful and stimulating way of teaching in this field. For planning is not only about the application of theory to practice but about the exploration of theory through practice. It is also, and perhaps above all, a transitive activity; it is about defining and solving specific problems, about acting on an object, and, as I have already suggested, the nature of the object is itself a determinant of the form of action taken-a 'rational' planning approach in one context with reference to one problem, might be an 'irrational' approach in another context or with another problem.

For all these reasons the embodiment of teaching within a 'practical'. or 'problem-solving' context is itself a way of getting at the essence of planning, for real planners always have a specific problem or set of problems to solve 'now', and must think and act in context. Within the framework of a university, simulation offers perhaps 
the only way of reproducing at least something of that 'situational', context-bound, problemoriented thinking, and of giving students something to plan in order to help them explore the adequacies and inadequacies of what currently passes for 'planning theory'.

\section{References}

Armstrong, R. H. R., and J. R. Taylor (eds.), 1970, Instructional Simulation Systems in Higher Education, Monographs in Teaching Methods No. 2, CUP, Cambridge

Chenery, H., and others, 1974, Redistribution with Growth, OUP, London

Faludi, A., 1973, Planning Theory, Pergamon Press, London

Friedmann, J. R. P., 1966, Regional Development Policy: A Case Study in Venezuela, M.I.T. Press, Cambridge, Massachusetts

${ }^{*}$ Gish, O., 1975, Planning the Health Sector: the Tanzanian Experience, Croom Helm, London

Griffin, K. B., and J. L. Enos, 1971, Planning Development, Addison-Wesley, London

Guetzkow, H., P. Kotler and R. L. Schultz, 1972, Simulation in Social and Administrative Science, Prentice-Hall

Hanson, A. H., 1966, The Process of Planning: A Study of India's Five-Year Plans, 1950-64, OUP, London

*Jolly, R., 1969, Planning education for African development: economic and manpower perspectives, East African Publishing House, Nairobi

*Kahn, A. J., 1969, Theory and Practice of Social Planning, Sage Foundation, New York
*Livingtone, A. S., 1969, Social Policy in Developing Countries, Routledge \& Kegan Paul, London

Organisation for Economic Cooperation \& Development, 1968, Budgeting, Programme Analysis \& Cost-Effectiveness in Education, OECD, Paris

Parish, C. M., 1977, Teaching \& learning methods and materials in selected university courses for overseas students, Agricultural Extension and Rural Development Centre, University of Reading

Taylor, J. L., 1969, Social Science instruction simulation systems: a selected bibliography, Project Paper 4, Research Institute for Social Science, Sheffield University

Tinbergen, J., 1967, Development Planning, Weidenfeld \& Nicholson, London

*United Nations Correspondence Course in Social Planning, 1972, Lecture 4, UNRISD, Geneva

*United Nations Dept. of Economic \& Social Affairs, 1968, Planning for balanced economic \& social development, UNDESA, New York

*United Nations Dept. of Economic \& Social Affairs, 1970, Social Welfare planning in the context of national development plans, UNDESA, New York

* United Nations Dept. of Economic \& Social Affairs, 1970, Social policy and the distribution of income in the nation, UNDESA, New York

*United Nations Research Institute for Social Development, 1966, Cost-Benefit Analysis of Social Projects, UNRISD, Geneva

Wàterston, A., 1966, Development Planning: Lessons of Experience, OUP, London

* Books on social development planning 